\title{
EDITORIAL
}

\section{Lung cancer detection by canine scent: will there be a lab in the lab?}

\author{
M. McCulloch*, K. Turner ${ }^{\#}$ and M. Broffman*
}

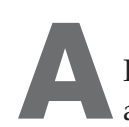
team of researchers led by R. Ehmann at Ambulante Pneumologie (Stuttgart, Germany) have published an article in the current issue of the European Respiratory Journal reporting on a study in which trained dogs detected lung cancer with sensitivity of $90 \%$ and specificity of $72 \%$ [1]. Their well-designed study involved 60 lung cancer patients and 110 healthy controls, and is novel for also including "disease controls"; 50 patients with non-malignant lung disease. The findings of EHMANN et al. [1] corroborate the results of an earlier study of canine scent detection of lung cancer, which reported sensitivity and specificity of $99 \%$. Together, these two papers, which achieved high accuracy while using different dogs, trainers and human subjects, beg the question of where this might all be leading. The purpose of this article is to review the evidence for canine scent detection of human cancers, and focus on how these papers may help advance knowledge in the field of lung cancer. There are very few published data on canine scent detection of cancers in general, or lung cancer in particular, and they vary widely in accuracy achieved and disease studied. However, the high accuracy of canine scent detection of lung cancer suggests dogs might, in the future, make some modest contribution to successes in lung cancer screening and detection.

\section{CURRENT METHODS FOR LUNG CANCER DETECTION FACE MANY CHALLENGES}

The goal of accurate, safe and noninvasive methods to detect lung cancer in its early and curable stages is shared by patients, researchers and clinicians worldwide. However, lung cancer is all too often diagnosed at late stages. Lung cancer is the leading cause of cancer deaths across the European Union, both in terms of standardised mortality rates and absolute numbers of people dying [2]. In 2010, an estimated 220,000 new cases of lung cancer were diagnosed, and over 150,000 deaths occurred, making it the leading cause of cancer death in both males and females in the USA [3]. Early detection of lung cancer remains a challenge, despite recent evidence from the ongoing National Lung Screening Trial in the USA showing that lung cancer mortality can be reduced by up to $20 \%$ with low-dose spiral computed tomography (CT) screening compared to chest radiography [4].

*Pine Street Foundation, San Anselmo, CA, and ${ }^{\#}$ EZ Train, El Sobrante, CA, USA.

CORRESPONDENCE: M. McCulloch, Pine Street Foundation, 124 Pine Street, San Anselmo, CA 94960-2674, USA. E-mail: mcculloch@pinestreetfoundation.org
While patients diagnosed with advanced lung cancer have a 5-yr survival rate of $<5 \%$, survival can increase to $>70 \%$ for patients whose disease is identified early when the lesion is small and localised [4]. However, at first diagnosis, over $75 \%$ of patients have advanced stage disease. Identifying lung cancer early is crucial to improve treatment outcomes and patient survival. The low sensitivity of chest radiographs, combined with the low specificity and high radiation dose of CT scanning, limit the reliability and safety of these technologies as screening tools. Furthermore, cumulative radiation exposure resulting from the use of repeated CT scanning can increase the risk of developing cancer [5].

\section{EXHALED BREATH ANALYSIS: DOGS ARE ONE OF MANY DIFFERENT TYPES OF SCENT DETECTORS}

An alternative strategy to lung cancer detection is the improved accuracy that can be gained from combining several tests as screening tools; one possible candidate may be the use of exhaled breath analysis.

There is strong biological plausibility to the idea of dogs detecting lung cancer in exhaled breath. Both our paper [6] and that of EHMANN et al. [1], in the current issue of the European Respiratory Journal, used an independent validation phase in which dogs were able to distinguish lung cancer patient breath samples from controls, using samples from individuals not previously encountered in their training. Nevertheless, critics may turn up their nose at the mention of using sniffer dogs.

This may arise in part because there are very few published data on canine scent detection of cancers in general $(n=8)[1,7-13]$, or lung cancer in particular $(n=2)[1,9]$. The findings of these studies vary widely in accuracy achieved and types of cancer studied, and papers on either replication of early findings or screening trials have not yet been published [14, 15]. It can be said, however, that the high-quality papers among those published, in which the investigators used rigorous patient selection, sample handling and dog training methods, have shown promising results.

Work toward the development of an "electronic nose" for cancer detection has been underway for several decades; however, dogs still appear to be ahead in the race and seem to have sniffed their way to the front of the line. We recently published a systematic review of all known data on the evidence for cancer biomarkers in exhaled breath [16], and a limited number of other research teams have published pilot data on exhaled breath analysis in lung cancer. There are no agreed upon standards for sampling methods or detection technology platform, each of 
these methods has limitations hampering their use for highly accurate lung cancer screening, and none have achieved the high sensitivity and specificity seen with dogs.

\section{DETECTING HUMAN DISEASE BY ODOUR HAS A LONG HISTORY}

The first published report of detecting human disease in a specific organ system by odour appeared in a 3rd century BC Chinese medical text, the Nan Jing Classic of Difficulties.

“五藏一病, 軴有五色, 色青者肝也, 臊臭者肝也 [Every disease of the five solid organs is reflected in (externally observable) colour and smell. For diseases of the liver, it is a greenish colour and rank odour]" (author's translation).

An earlier writing by Hippocrates (ca. $460 \mathrm{BC}$ to ca. $370 \mathrm{BC}$ ) included a more general mention of odour changing in febrile patients in the medical text Hippocratic Corpus, Prorrhetics II.

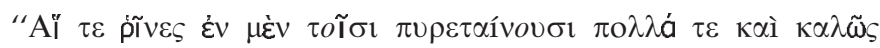

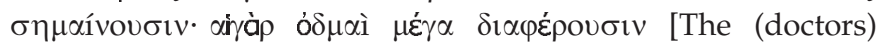
nostrils indicate much and well in (the case of) fever patients; the odours, however, differ a lot]" (translated by R. Christo).

\section{Cancer detection by dogs}

The first publication of a dog detecting cancer is the case of a young female from the UK who remarked to a dermatologist examining a suspicious mole on her leg, that her dog had been licking, nipping and barking energetically and persistently at the lesion [12]. The subject of this paper was then interviewed for a television documentary broadcast in 2006 in the UK [17]. Following the publication of our group's lung and breast cancer paper [9], several dozen people have written letters reporting a similar story (data not shown).

\section{A vision for the role of dogs in detecting cancer}

Since we began our work in canine scent detection of lung cancer 10 yrs ago, we have frequently heard patients, clinicians and researchers lament about several critical issues at conferences, presentations and during scent trials: 1) the frustrations related to the slow progress in the forward movement of science, specifically with early detection; and 2) the anxieties caused by false positives and regrets resulting from false negatives, with current cancer screening and diagnostic methods. These comments from patients are understandable, given the frequent reports in the media about problems with lung cancer detection methods, whether it be the poor ability to detect lung cancer with chest radiographs, the hazards of cumulative radiation from CT scans, or the poor resolving power with small modules of the positron emission tomography (PET) scan.

However, imagine a future in which the term PET takes on a new meaning. Dogs could serve as an inspirational role, with the story of dogs detecting cancer in rigorous trials used as a friendly message to the public, perhaps encouraging patients who may be reluctant to seek medical help to do so.

Dogs could also serve a more pragmatic role. If enough funding were allocated to allow other research groups to replicate and refine the encouraging results of the two existing papers on canine scent extension of lung cancer [1,9], dogs could be used as a noninvasive preliminary diagnostic screening tool or be used to help reduce false positives and false negatives of existing imaging technologies. This would maximise the power of joint probabilities, similar to the combination of prostate specific antigen and digital examination being more accurate than either method alone for detecting prostate cancer, or CA125 and transvaginal ultrasound for detecting ovarian cancer.

In both the literal and the metaphorical sense, with the publication of these papers on canine scent detection of lung cancer, dogs are once again demonstrating their ability to serve as our protectors and guides. People worldwide feel a close affinity with the dog as a friend and protector. Dogs also serve us faithfully in their dilagent work at finding cadavers, bombs, drugs, weapons and truffles, detecting diabetes and seizures, conducting search and rescue, providing sighting assistance and giving loving companionship. Whether or not sniffer dogs actually make it into the continuum of diagnostic evaluation has yet to be seen; their image could be employed in public health outreach for cancer screening, and may encourage people with worrisome symptoms to take earlier action. This would be a case of the dog acting as a shepherd; Lassie and Rin Tin Tin are still out there, looking out for our health.

\section{STATEMENT OF INTEREST}

None declared.

\section{REFERENCES}

1 Ehmann R, Boedeker E, Friedrich U, et al. Canine scent detection in the diagnosis of lung cancer: revisiting a puzzling phenomenon. Eur Respir J 2012; 39: 669-676.

2 Malvezzi M, Arfe A, Bertuccio P, et al. European cancer mortality predictions for the year 2011. Ann Oncol 2011; 22: 947-956.

3 Jemal A, Siegel R, Xu J, et al. Cancer statistics, 2010. CA Cancer J Clin 2010; 60: 277-300.

4 Aberle DR, Berg CD, Black WC, et al. The National Lung Screening Trial: overview and study design. Radiology 2011; 258: 243-253.

5 Sodickson A, Baeyens PF, Andriole KP, et al. Recurrent CT, cumulative radiation exposure, and associated radiation-induced cancer risks from CT of adults. Radiology 2009; 251: 175-184.

6 McCulloch M, Jezierski T, Broffman M, et al. Diagnostic accuracy of canine scent detection in early- and late-stage lung and breast cancers. Integr Cancer Ther 2006; 5: 1-10.

7 Gordon RT, Schatz CB, Myers LJ, et al. The use of canines in the detection of human cancers. J Altern Complement Med 2008; 14: 61-67.

8 Horvath G, Jarverud GA, Jarverud S, et al. Human ovarian carcinomas detected by specific odor. Integr Cancer Ther 2008; 7: 76-80.

9 McCulloch M, Jezierski T, Broffman M, et al. Diagnostic accuracy of canine scent detection in early- and late-stage lung and breast cancers. Integr Cancer Ther 2006; 5: 30-39.

10 Pickel D, Manucy GP, Walker DB, et al. Evidence for canine olfactory detection of melanoma. Appl Anim Behav Sci 2004; 89: 107-116.

11 Sonoda H, Kohnoe S, Yamazato T, et al. Colorectal cancer screening with odour material by canine scent detection. Gut 2011; 60: 814-819.

12 Williams H, Pembroke A. Sniffer dogs in the melanoma clinic? Lancet 1989; 1: 734 .

13 Willis CM, Church SM, Guest CM, et al. Olfactory detection of human bladder cancer by dogs: proof of principle study. BMJ 2004; 329: 712.

14 Moser E, McCulloch M. Canine scent detection of human cancers: a review of methods and accuracy. J Vet Behav 2010; 5: 145-152.

15 Lippi G, Cervellin G. Canine olfactory detection of cancer versus laboratory testing: myth or opportunity? Clin Chem Lab Med 2011 [Epub ahead of print DOI: 10.1515/cclm.2011.672].

16 Szulejko JE, McCulloch M, Jackson J, et al. Evidence for cancer biomarkers in exhaled breath. IEEE Sensors J 2010; 10: 185-210.

17 Can Dogs Smell Cancer? Storyville. BBC television documentary 2006. Available from: www.passionateproductions.co.uk/film_can_dogs.htm 